\title{
Weibull Modeling of Controlled Drug Release from Ag-PMA Nanosystems
}

\author{
Carmelo Corsaro $^{1}\left(\mathbb{D}\right.$, Giulia Neri ${ }^{2}(\mathbb{D})$, Angela Maria Mezzasalma ${ }^{1}$ and Enza Fazio $^{1, *(D)}$ \\ 1 Department of Mathematical and Computational Sciences, Physics Science and Earth Science, \\ University of Messina, Viale F. Stagno D’Alcontres 31, I-98166 Messina, Italy; ccorsaro@unime.it (C.C.); \\ angelamaria.mezzasalma@unime.it (A.M.M.) \\ 2 Department of Chemical, Biological, Pharmaceutical and Environmental Sciences, University of Messina, \\ Viale F. Stagno D'Alcontres 31, I-98166 Messina, Italy; giulia.neri@unime.it \\ * Correspondence: enfazio@unime.it
}

check for updates

Citation: Corsaro, C.; Neri, G.;

Mezzasalma, A.M.; Fazio, E. Weibull Modeling of Controlled Drug Release from Ag-PMA Nanosystems. Polymers 2021, 13, 2897. https:// doi.org/10.3390/polym13172897

Academic Editor:

Barbara Klajnert-Maculewicz

Received: 31 July 2021

Accepted: 24 August 2021

Published: 27 August 2021

Publisher's Note: MDPI stays neutral with regard to jurisdictional claims in published maps and institutional affiliations.

Copyright: (c) 2021 by the authors. Licensee MDPI, Basel, Switzerland. This article is an open access article distributed under the terms and conditions of the Creative Commons Attribution (CC BY) license (https:// creativecommons.org/licenses/by/ $4.0 /)$

\begin{abstract}
Traditional pharmacotherapy suffers from multiple drawbacks that hamper patient treatment such as antibiotic resistances or low drug selectivity and toxicity during systemic applications. Some functional hybrid nanomaterials are designed to handle the drug release process under remote-control. More attention has recently been paid to synthetic polyelectrolytes for their intrinsic properties which allow them to rearrange into compact structures, ideal to be used as drug carriers or probes influencing biochemical processes. The presence of Ag nanoparticles (NPs) in the Poly methyl acrylate (PMA) matrix leads to an enhancement of drug release efficiency, even using a low-power laser whose wavelength is far from the Ag Surface Plasmon Resonance (SPR) peak. Further, compared to the colloids, the nanofiber-based drug delivery system has shown shorter response time and more precise control over the release rate. The efficiency and timing of involved drug release mechanisms has been estimated by the Weibull distribution function, whose parameters indicate that the release mechanism of nanofibers obeys Fick's first law while a non-Fickian character controlled by diffusion and relaxation of polymer chains occurs in the colloidal phase.
\end{abstract}

Keywords: Ag nanoparticles; Poly(methacrylic acid) sodium salt; photoreduction process; Weibull function; statistical distributions; drug nanocarrier; smart nanodevice

\section{Introduction}

Nowadays several efforts are focusing on the development of eco-friendly approaches to reduce the environmental impact of industrial production. To reach this goal, bottom-up techniques concerning the design of nanodevices able to efficiently perform one or more tasks [1] in the field of artificial photosynthesis [2,3], biomedicine [4,5], non-invasive diagnostic techniques $[6,7]$, food packaging $[8,9]$ are receiving ever-growing attention due to the versatility in the modulation of their properties. On the other hand, the use of biomaterials is crucial to preserve human and the ecosystem's health. However, the low chemical-physical stability, short lifetime and poor mechanical properties of these materials limit their extensive employment. To overcome these hurdles, the incorporation of materials of different nature in a bio matrix allows achievement of hybrid nano-systems showing improved properties compared to the starting ones $[10,11]$. In the biomedical field, the necessity to provide smart drug nanocarriers able to keep the drug concentration within its therapeutic window avoiding under-dosing (inefficient treatment) or over-dosing (cytotoxicity) phenomena such as multidrug resistance effects, led to design stimuli-responsive drug delivery systems [12-14].

Among the several kinds of nanodevices, polymer matrix based nanocomposites have emerged as the most promising and viable systems in the food industry [15] as well as in drug nano-delivery systems [16]. The incorporation of pharmaceuticals into electrospun polymeric fibers has several advantages such as high porosity and high surface area to 
volume ratio, obtaining a system similar in structure to extra cellular membrane [17]. Further, to increase drug collection/release efficiency in a nanofiber system, controlled wetting properties are desirable [18]. Thus, fiber systems are employed to reach both immediate and controlled drug release processes $[19,20]$.

At the same time, stimuli-responsive bio-based polymeric systems are gaining considerable attention as intelligent versatile tools that show great potential in the food packaging field. The idea is that when a beneficial interaction between the packaging, environment and food occurs, the bioactive compound is released under control [21]. Moreover, the development of multifunctional polymer-based nanocomposites exhibiting several functionalities combined in a single device is one of the most favorable approaches to reach new smart materials [22-24]. In this perspective, silver nanoparticles (Ag NPs) are considered one of the most promising candidates in biomedical applications thanks to their multiple functions $[25,26]$. In addition, recent research has shown promising results for their innovative and potential applications in the food field, which also include their integration into intelligent food packaging systems and their direct incorporation into food matrices as a flavor carrier system [27]. However, despite the remarkable advantages and innumerable positive properties of Ag NPs, safety concerns have been raised over their usage because they pose potential environmental hazards [28]. It is worth mentioning that Ag NPs can affect aquatic photosynthetic organisms [29], and they are also able to induce oxidative and genotoxic damages on organisms and cells [30]. Therefore, the prevention of Ag NPs diffusion in the biosphere is a pivotal step in the design of new and effective systems based on Ag NPs.

To achieve this goal, particular attention has been devoted towards the use of polyelectrolytes which act both as reducing and stabilizing agents, avoiding the use of surfactants. Synthetic polyanions are widely employed in the medical field as arthritis adjuvants, promoters of the endosomal escape, modulators of the phagocytic activity and drug delivery systems [31,32]. Among these synthetic polyanions, poly methyl acrylate (PMA) offers several advantages such as: (i) water solubility, (ii) capping agent thanks to the ability to wrap of metal clusters [33] and (iii) good biocompatibility, which is proved by its employment in biomedicine and biotechnology fields [34-36]. Moreover, it was demonstrated that the stability of its compact form is the result of a combination of several forces including (i) short-range van der Waals forces correlated to methyl side chains, hydrophobic interactions and (ii) hydrogen bonding, which involves the carboxyl functional groups [32]. Lastly, PMA is characterized by a water contact angle of $\sim 73^{\circ}$ [37], a higher value compared

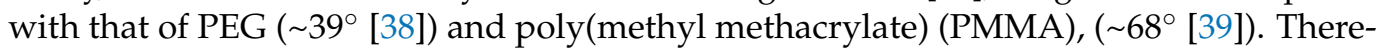
fore, its low hydrophilicity allows maintaining its mechanical properties when absorbing water. Considering the relevance of wettability properties in the drug release process, the intrinsic physical and chemical features of PMA make it a promising candidate as a drug nanocarrier.

Herein, Ag-PMA colloidal solution was prepared by a green and eco-friendly UV photoreduction procedure [40,41]. PMA acts as capping agent allowing well-defined and low distribution in the size of the hybrid nanocolloid ( $\sim 10 \mathrm{~nm}$ diameter). Then, Sorafenib Tosylate (SFT), a promising hydrophobic ( $\log \mathrm{P}=3.8)$ anticancer drug [42], was embedded in Ag-PMA matrix. The drug release profiles of the prepared nanocolloid and the corresponding electrospun Ag-PMA nanofibers scaffold, were analyzed by a Weibull statistical distribution function, gaining physical insights on the mechanisms governing drug release. Since the original work of Waloddi Weibull [43], the Weibull distribution has been applied to a great number of mechanisms for studying the kinetics of heterogeneous processes [44], also demonstrating its overall superiority for fitting the drug release by nanosystems [45]. The model-independent statistical simulation of in vitro release profiles was introduced by Koester et al. [46], who also established the supremacy of the Weibull model over other competing statistical models through linear regression analysis [47]. Generally, logistic approaches achieve a high degree of accuracy, although they require several parameters and a certain degree of complexity during the fitting process. It is 
worth to mention that, different mathematical models are usually used as tools to predict the drug release kinetics, investigating their applicability in specific time intervals [48]. In this work, after having checked some mechanistic models including power law and Higuchi models, we have chosen to use the continuous Weibull function (simpler than the logistic function) which fits the whole release process, providing a statistical description of it. The Weibull function has shown, in fact, better fitting performances with a good degree of accuracy and, above all, it allowed us to find some correlations among its parameters, the release process features and, in turn, with the morphological characteristics of the studied systems. The basic idea is to statistically interpret the normalized curve for the drug release kinetics as a cumulative distribution function (CDF), since its trend is monotonic increasing and reaches 1 (or $\mathrm{M}_{\infty}$, the maximum released drug amount) at large times. In such a way, we interpret the drug release kinetics as the probability of the drug to be released at a time $t$. Indeed, we use the Weibull cumulative distribution function (which is the complementary function of the stretched exponential form [49]), to obtain information about the average relaxation time and the Weibull shape factor, strictly related to the specific release mechanism. Furthermore, the time derivative of the Weibull CDF, representing the Weibull Probability Density Function (PDF), provides the probability of reaching the maximum of drug release at a time $t$ (corresponding to the drug release speed). Then, a correlation among Weibull parameters, release mechanisms and samples properties has been carried out. All that is essential for a better understanding of the release mechanisms and serves as a basis for designing innovative PMA based controlled release type formulations.

\section{Materials and Methods}

Poly(methacrylic acid) sodium salt $\left(\left[\mathrm{CH}_{2} \mathrm{C}\left(\mathrm{CH}_{3}\right)\left(\mathrm{CO}_{2} \mathrm{Na}\right)\right] \mathrm{n}, \mathrm{Mw}=9500\right)$ and silver nitrate powder $\left(\mathrm{AgNO}_{3}\right)$, were purchased from Merck (Milan, Italy) and used without further purification. Sorafenib Tosylate (SFT) was offered by the Department of Chemical, Biological, Pharmaceutical and Environmental Sciences, University of Messina (Messina, Italy).

\subsection{Ag-PMA NPs Formulation Strategy and Characterization}

A high purity (98\%) silver nitrate $\left(\mathrm{AgNO}_{3}\right)$ powder was dissolved into a $30 \%$ water solution of PMA (Poly(methacrylic acid) sodium salt, $\left(\left[\mathrm{CH}_{2} \mathrm{C}\left(\mathrm{CH}_{3}\right)\left(\mathrm{CO}_{2} \mathrm{Na}\right)\right]_{n}, \mathrm{Mw}=9500\right)$; up to 10:1 ( $\mathrm{AgNO}_{3} / \mathrm{PMA}$ ) molar ratio (Figure 1a). Ag NPs stabilized in PMA matrix were fabricated via reduction processes under a two-step UV irradiation to control the kinetics of NPs nucleation as well as to obtain a narrow size distribution [40,41]. In the first step, the mixture has been exposed for $1 \mathrm{~h}$ to a $6 \mathrm{~W}$ UV lamp irradiation (estimated density of $470 \mathrm{nW} / \mathrm{cm}^{2}$ ). After $5 \mathrm{~min}$ of exposure, the reduction in $\mathrm{Ag}^{+}$ions by PMA leads to a change of the color of the solution from colorless to yellow (see Figure 1b). In a second step, the mixture has been exposed for $5 \mathrm{~h}$ to $25 \mathrm{~W}$ UV lamp irradiation (estimated density $378 \mathrm{~mW} / \mathrm{cm}^{2}$ ). During this process, PMA aqueous solution acted as capping and reducing agent. The solution color turned to dark orange (see Figure 1b). 


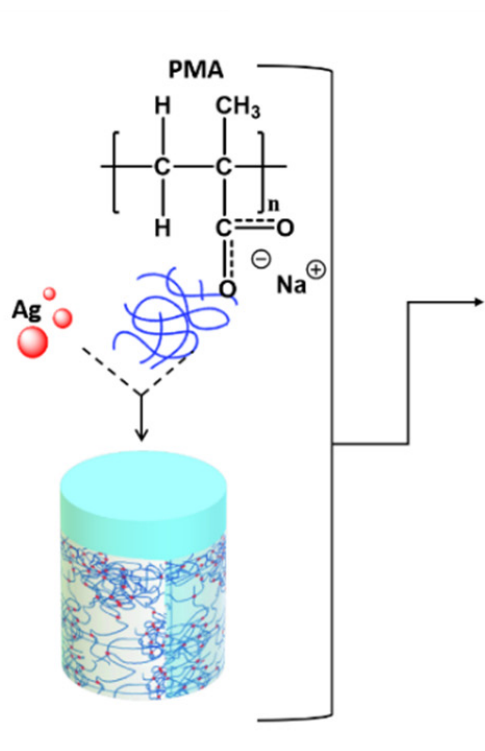

a)

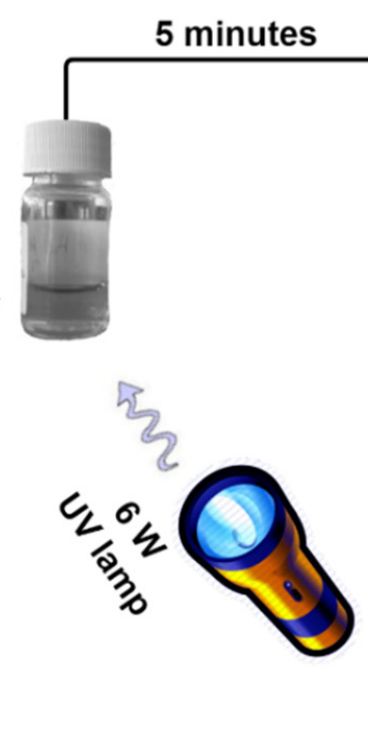

b)

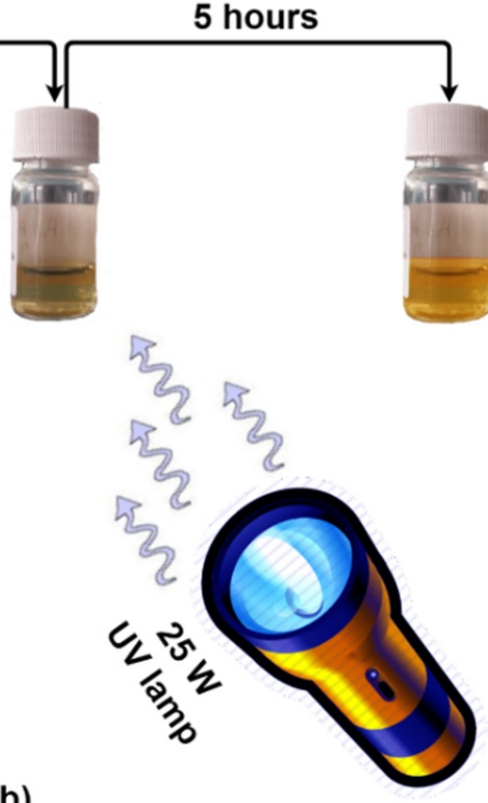

Figure 1. Schematic representation of the Ag-PMA colloid formulation strategy which consists in the dissolution of $\mathrm{AgNO}_{3}$ powder in PMA solution up to 10:1 molar ratio (a), followed by two-steps UV irradiation process (b).

The stability of the obtained solution has been monitored, after one month in air and dark conditions, carrying out Dynamic Light Scattering (DLS) measurements. A Horiba NanoParticle Analyzer SZ-100(Horiba, Grenoble, France), working in the $0.3 \mathrm{~nm}-8 \mu \mathrm{m}$ range, was used to determine Zeta potential values. The process results have been also monitored by UV-vis optical spectroscopy and Scanning Electron Microscopy working in Transmission mode (STEM) (ZEISS, Hamburg, Germany). The Perkin-Elmer Lambda 750 spectrometer (Perkin-Elmer, Waltham, MA, USA) was used to collect optical absorption spectra. Further, a Zeiss-Gemini 2 electron microscope, operating at the accelerating voltages of $150 \mathrm{kV}$ and $30 \mathrm{kV}$, has allowed aquirement of SEM and STEM images, respectively. To this purpose, a drop of each suspension was deposited on a 400 mesh carbon support sputter-coated with chromium and left to dry at room temperature for $2 \mathrm{~h}$.

X-ray diffraction (XRD) patterns of the sample were recorded using a Bruker AXS D8 advanced diffractometer (Bruker, Karlsruhe, Germany)with $\mathrm{CuK} \alpha$ radiation (=1.5406 Angstrom) in the range of $20-80^{\circ}$. The thermogravimetric weight loss curve was recorded as a function of temperature using a Mettler Toledo TGA(Mettler Toledo, Greifensee, Switzerland) apparatus in air. The sample weight was $2.5 \mathrm{mg}$. The sample was heated at the maximum programmed heating rate of $10{ }^{\circ} \mathrm{C} \mathrm{min}-1$. The weight loss was calculated by the difference between the weights at room temperature (RT) and at $500{ }^{\circ} \mathrm{C}$. The balance sensitivity was $0.1 \mathrm{mg}$.

\subsection{Drug Loading}

The drug loading process was performed as reported in Ref [50]. Briefly, $20 \mathrm{~mL}$ of SFT solution at the final concentration of $200 \mathrm{ppm}$ were prepared. Then, $500 \mathrm{mg}$ of Ag-PMA sample were added into the drug solution and dispersed by ultrasonication treatment (Sonics VCX 130). The mixture was stirred at room temperature for $24 \mathrm{~h}$.

The amount of SFT loaded in Ag-PMA system was spectrophotometrically estimated by the following strategy. A weight amount $(1 \mathrm{mg})$ of Ag-PMA loaded with SFT was well dissolved in $4 \mathrm{~mL}$ of PBS by sonication treatment and centrifuged at $6000 \mathrm{rpm}$ for $45 \mathrm{~min}$. The precipitate was collected, repeatedly washed to remove the free drug and finally lyophilized. The nanocomposite was dispersed in DMSO/PBS solution (1:99) and UV-vis spectra were recorded, following the drug absorbance signal at the wavelength of $265 \mathrm{~nm}$. 
Finally, a drug loading (DL\%) of 5.5\% and an encapsulation efficiency (EE\%) at about $60 \%$ were respectively computed by following the equations reported below [51]:

- $\mathrm{DL} \%=$ (drug weight encapsulated in the NPs / weight of the NPs) $\times 100$

- $\mathrm{EE} \%=$ (drug weight encapsulated in the NPs/weight of drug used in encapsulation strategy) $\times 100$

\subsection{Ag-PMA Nanofibres Preparation and Characterization}

Electrospinning process was selected to prepare nanofibrous scaffold with a setup consisting of a high voltage supply, a syringe pump and a collector improving the procedure described in Ref. [50]. Ag-PMA colloidal solution, loaded with SFT, was forced through a coaxial spinneret by two 10-mL syringe pumps. Electrospinning parameters (i.e., polymer solution feed rate, collection distance and applied voltage) were varied to limit beads formation. The formation of beads was avoided applying a voltage of $35 \mathrm{kV}$ DC between the spinneret and the collector plate, flushing the solution at a low flow rate (about $1 \mathrm{cc} / \mathrm{h}$ ). Then, the fibers were collected onto an aluminum foil positioned at a distance of $10 \mathrm{~cm}$ from the needle tip. The morphology of the nanofibers was investigated by SEM, while Ag NPs distribution in PMA matrix was detected by EDX probe (SE: secondary electron imaging).

\subsection{Drug Release}

The dialysis method was adopted to perform the in vitro release experiments of Ag-PMA nanocolloids [52]. In details, $4 \mathrm{mg}$ of Ag-PMA system loaded with SFT were dispersed in $4 \mathrm{~mL}$ of $10 \mathrm{mM}$ PBS at $\mathrm{pH} 7.4$ and sonicated for $1 \mathrm{~h}$. The dialysis bag (MWCO $=3.5-5 \mathrm{kDa}$ Spectra/Porr) was filled with the colloidal solution and submerged by $15 \mathrm{~mL}$ of PBS solution.

Conversely, the drug release experiments involving the Ag-PMA electrospun nanofibers, were performed by submerging the system in $10 \mathrm{mM} \mathrm{PBS}$ at pH 7.4, as reported in the literature [53]. In both cases the system was kept at $37^{\circ} \mathrm{C}$, under constant stirring. Then, $1 \mathrm{~mL}$ of the release medium was withdrawn, replaced with an equal volume of a fresh one, and finally analyzed by UV-Vis optical spectroscopy at fixed time intervals. The experiments were carried out in duplicates with a continuous He-Ne laser as source $\left(\lambda=632 \mathrm{~nm}\right.$, energy density $\left.=21 \mathrm{~mW} / \mathrm{cm}^{2}\right)$.

\section{Results}

\subsection{Ag-PMA Nanosystems Formulation and Characterization}

A nanohybrid Ag-PMA system was prepared by a UV-vis $\mathrm{AgNO}_{3}$ photoreduction process $[40,41]$, and the colloidal stability of the obtained nanocomposite was monitored at different irradiation time by carrying out UV-vis optical absorption measures. The intensity of the plasmon resonance band at about $425 \mathrm{~nm}$ slightly increases with irradiation time as shown in Figure $2 \mathrm{a}-\mathrm{c}$. It was also observed that, by varying the exposure time from 5 to $60 \mathrm{~min}$, the peak width decreases progressively of some nanometers, while its band intensity increases (Figure 2b). At irradiation time longer than $300 \mathrm{~min}$, the plasmonic peak becomes wider and another broad band around $620 \mathrm{~nm}$ appears (Figure 2c). These changes can be attributed to the occurrence of NPs nucleation process [54]. Assuming that the plasmonic peak is representative of the NPs nucleation, while the peak at $500 \mathrm{~nm}$ represents the formation of NPs aggregates, the above results suggest that the NPs aggregation process starts when the nucleation has been almost completed (see Figure 2e). It is important to remark that the plasmon intensity, which is related to the nucleation mechanism, grows up faster than the intensity of the $620 \mathrm{~nm}$ absorbance band. This suggests that the NP nucleation mechanism is faster than the subsequent NP growth. Considering the previous results, $1 \mathrm{~h}$ exposure at $470 \mathrm{nW} / \mathrm{cm}^{2}$ was chosen as the first step of the reducing process. Moreover, UV-vis optical absorbance spectra after the first and second step of irradiation are very similar (Figure 2d), indicating that the polymer reticulates during the second step strongly limit any further Ag NPs nucleation, growth, and aggregation processes. 

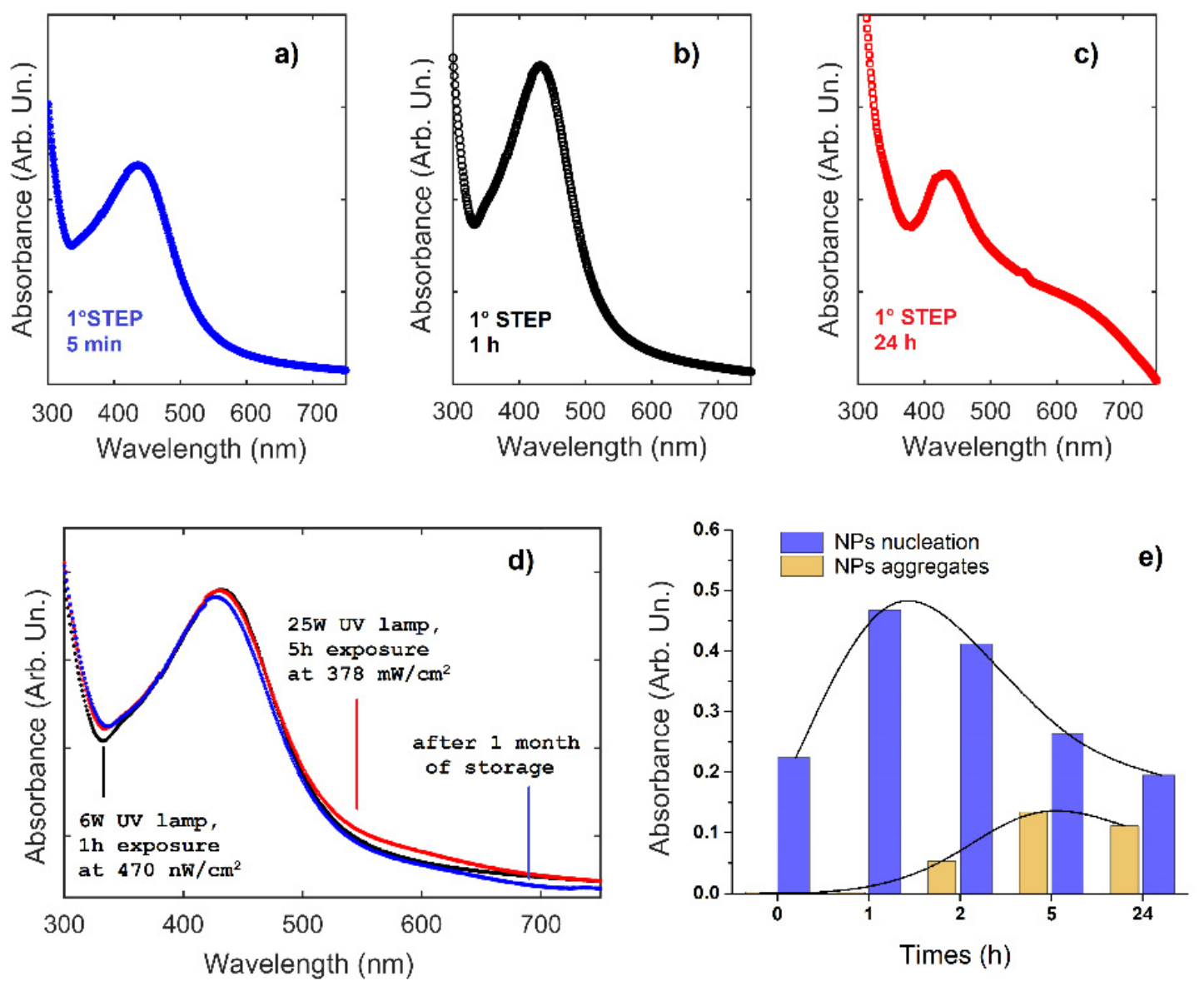

Figure 2. UV-vis optical absorbance spectra at different times during the first $(\mathbf{a}-\mathbf{c})$ and second (d) step of UV irradiation treatment to prepare Ag-PMA nanocolloid. The spectrum after one month by the second step of irradiation is also shown (d). The optical absorbance value vs. time is reported in panel (e) for the two main processes (NPs nucleation and aggregates).

The stability of the obtained nanohybrid Ag-PMA colloidal system was monitored by the optical absorbance features previously described. After a one-month storage period in air and dark conditions, the size and shape of the Ag-PMA nanocolloid remain almost unchanged (see STEM images in Figure 3a-c and UV-vis optical absorption spectra in Figure $3 \mathrm{~d}$ ). The good stability of this nanohybrid system is also corroborated by the observed Zeta potential (ZP) value and the intensity distribution data. ZP value is of about $-45.0 \mathrm{mV}$ after the first irradiation step, about $-38.0 \mathrm{mV}$ after the second irradiation step and one month of storage (Figure 3d), proving the high colloidal stability of Ag-PMA system. Only after three months of storage, a bimodal intensity distribution and ZP values up to $-30 \mathrm{mV}$ are found.

The XRD pattern of the Ag-PMA nanocolloid was also investigated (Figure 4a). The $\mathrm{Ag}$ crystal phase within the PMA matrix is indicated by the XRD peaks centered at $19.35^{\circ}$, $37.99^{\circ}, 44.06^{\circ}, 64.57^{\circ}$ and $77.29^{\circ}$, and corresponding to the (111), (200), (220) and (311) planes of the Ag face-centered cubic (fcc) crystal structure [55]. Furthermore, the thermal stability of Ag-PMA was evaluated by thermogravimetric analysis (TGA). TG curves showed a lower thermal stability of the hybrid Ag-PMA system respect to the pure PMA system (Figure 4b). This trend is due to the homogeneous distribution of Ag NPs in the polymer matrix (see Figure 3), which induces a rapid heating effect, aiding the decomposition of the PMA matrix [35]. A percentage residual mass of $4.8 \%$ was estimated for the Ag-PMA sample, which corresponds to the amount of Ag NPs loaded into the polymer matrix. No residual mass was detected for PMA sample. 
a)

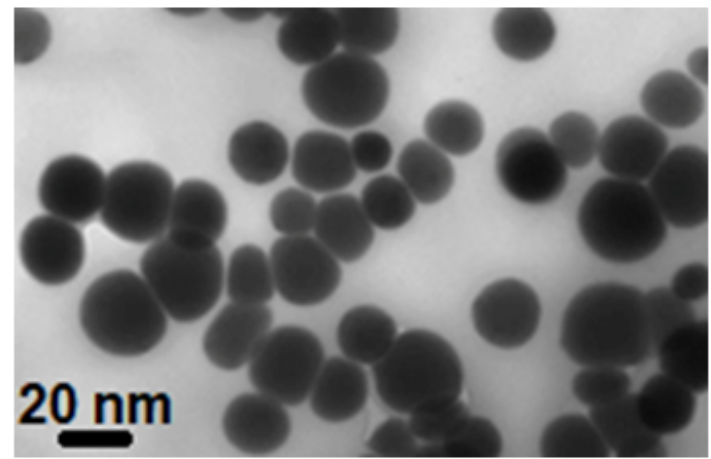

c)

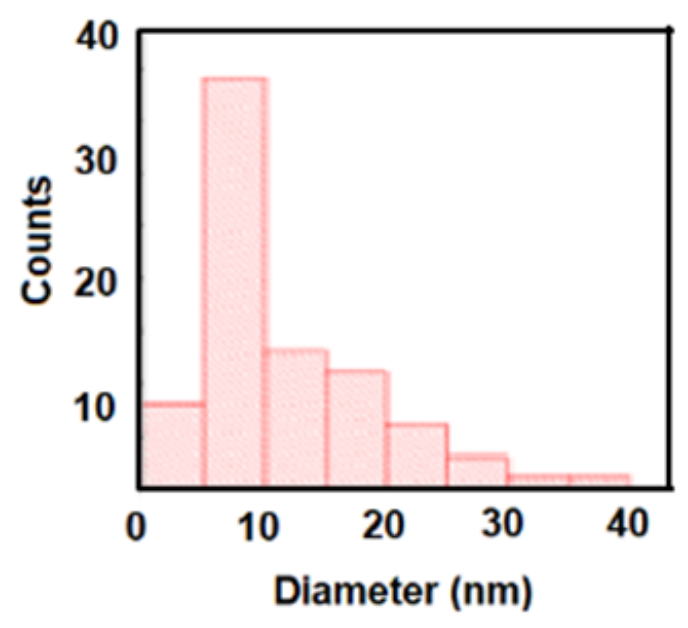

b)

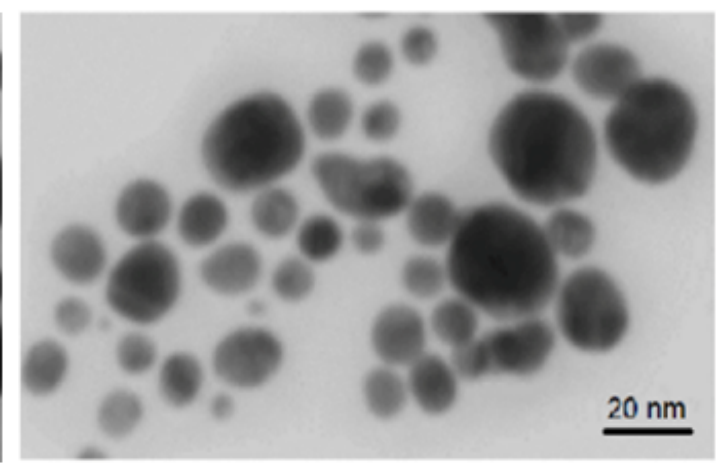

d) $\times 10^{5}$

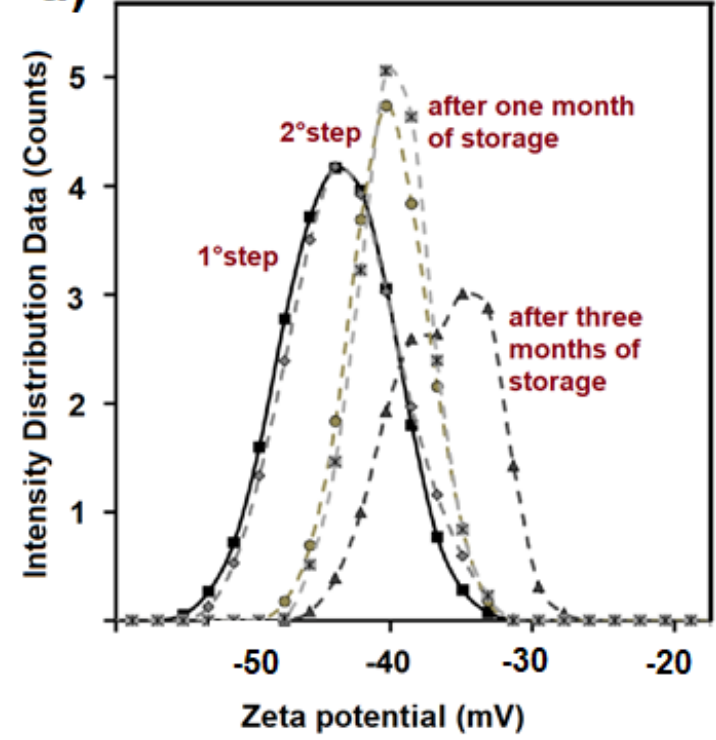

Figure 3. STEM images $(\mathbf{a}, \mathbf{b})$ of Ag-PMA nanocolloid (before and after one month of storage) and the corresponding size distribution histogram obtained by using Matlab Toolbox for image analysis (c). Zeta potential values of Ag-PMA colloidal solution at different conditions $(\mathbf{d})$ are reported.
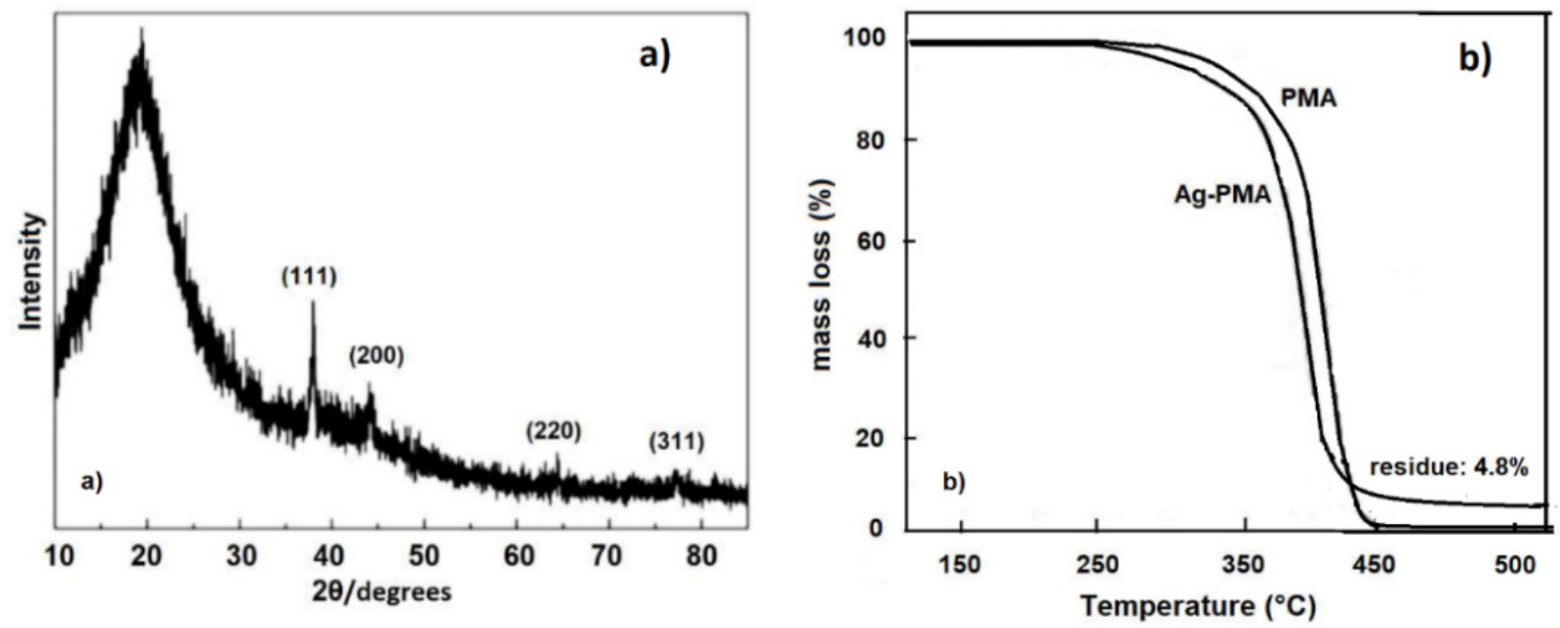

Figure 4. In panel (a) the XRD spectrum of Ag-PMA nanocolloid is reported, while in panel (b) the TG curves of Ag-PMA nanohybrid colloid and alone PMA, are shown. 
Rapid dissolution, increased drug solubility and bioavailability are important factors to control the delivery rate. One useful approach to achieve this goal is to load active pharmaceutical ingredients by the electrospinning technique, since this is a method that produces ultra-fine fibers (from micro- to nanometers of diameter), with controlled surface morphology. In our case, an electrospinning technique was used to produce the SFTloaded Ag-PMA nanofibrous scaffold. Figure 5a shows a representative SEM image of the Ag-PMA nanofibers after an optimization of the electrospinning procedure. The nanofibers, randomly oriented, are characterized by a porous structure and a diameter of about $100-200 \mathrm{~nm}$. As can be envisaged in Figure 5b, EDX probe allows visualization of a uniform distribution of Ag NPs (5-25 nm in size) along the electrospun scaffold. The pore size is less than $20 \mathrm{~nm}$ (Figure 5c) and Ag NPs are embedded within the porous nanostructure (Figure 5d).

a)

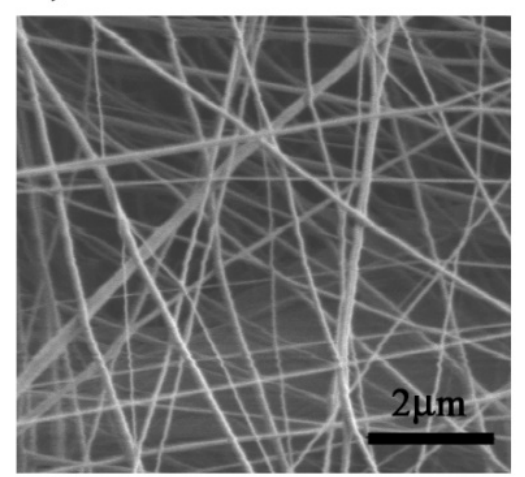

c)

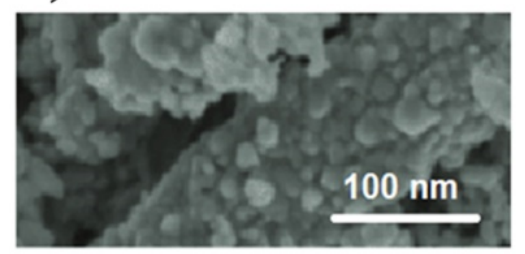

b)

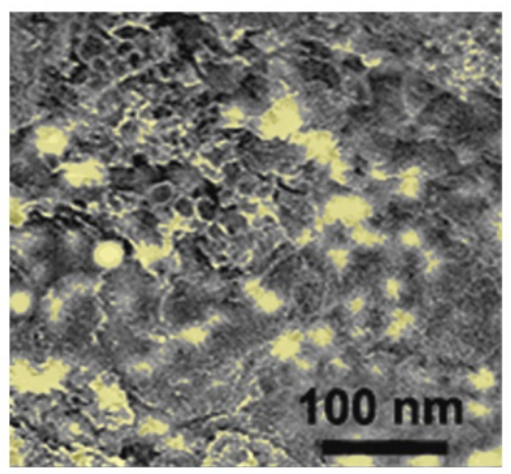

d)

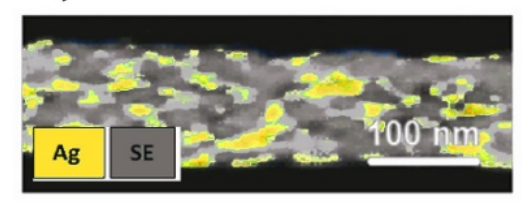

Figure 5. SEM images (a-c) and EDX analysis (d) for the Ag-PMA electrospun scaffold.

\subsection{Drug Release}

To fabricate controlled drug release devices, we combined the properties of the PMA polyelectrolyte with those of Ag NPs. Ag-PMA nanocolloid was loaded with SFT, a hydrophobic drug, and a drug loading percentage (DL\%) of $\sim 5.5 \%$ and an encapsulation efficiency percentage (EE\%) of $\sim 60 \%$ were respectively evaluated [50]. Subsequently, AgPMA colloidal solution was electrospinned to prepare Ag-PMA nanofibers loaded with SFT. We investigated both the spontaneous drug release processes and the triggered ones. In the last cases, Ag-PMA systems were laser irradiated at $632.8 \mathrm{~nm}$ and displayed two different drug release profiles.

To initially check for a possible simple power-law approach and infer the character of the release mechanism, we show in Figure 6a the log-log plot of the drug release percentage versus the release time for all samples. Data show a linear correlation (and then the release kinetics can be described by a power law) over a different time, up to the saturation release percentage value. The corresponding linear fits (whose slope provides the first information about the release mechanism) are also shown. We obtain a slope of $0.88 \pm 0.09$ for the non-irradiated system suggesting a zero order kinetic mechanism for drug release [56,57], $(2.57 \pm 0.12)$ and $(0.48 \pm 0.02)$ for the light irradiated samples (triangle symbols for the colloids and square symbols for the nanofibers system), respectively. According to theory [56], the highest estimated slope for the irradiated colloidal systems indicates that the release mechanism is quite complex since several internal collective processes may have occurred (polymer degradation, polymer swelling and so on). On the 
contrary, a slope of about 0.5 , as that obtained for nanofibers, indicates that the initial drug release process could be described by a diffusion process [58]. Then, in Figure 6b, we report the same data in the so-called Weibull plot form (showing the linearization of the Weibull distribution reported in Equation (1) in the double logarithmic form). All that to check if the Weibull function can be efficiently used to reproduce the whole release process for all the investigated conditions [47]. The obtained slope provides a first estimation of the Weibull exponent $\beta$, better described below. As reported in Figure $6 \mathrm{~b}$, we obtain a slope of $1.02 \pm 0.04$ for the non-irradiated samples, $(2.63 \pm 0.09)$ and $(0.75 \pm 0.02)$ for the light irradiated samples (triangle symbols for the colloids and square symbols for the nanofibers system), respectively.
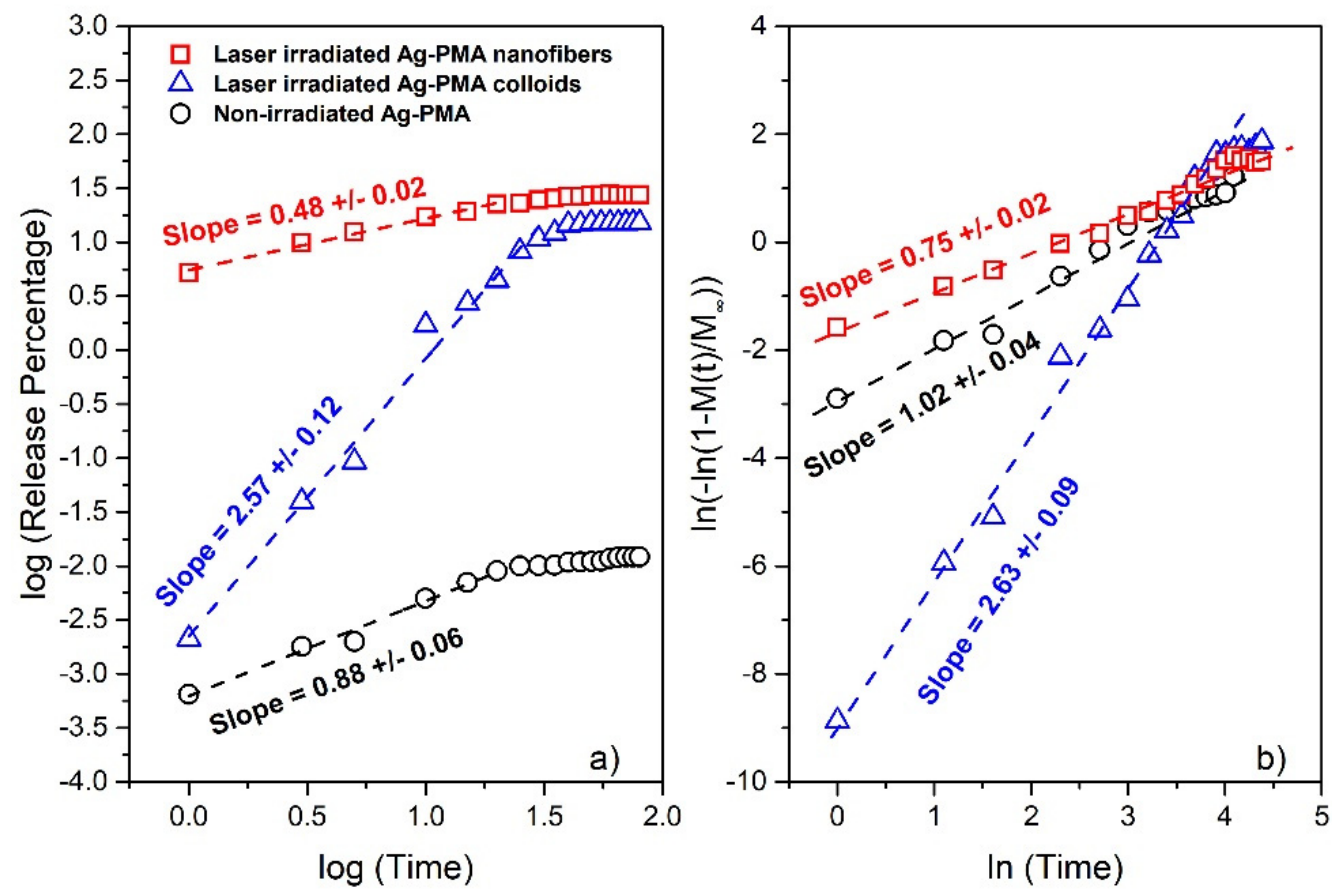

Figure 6. Log-log plot of the drug release percentage vs. time in hours for SFT embedded in PMA-Ag matrix at different conditions (a). Linear correlations, corresponding to power law behavior, can be observed only for the initial release. Weibull plot of the same data to check if the Weibull function can be used to reproduce the whole release process for all the studied conditions (b). Data for the non-irradiated system refer to both colloids and nanofibers. In Figure S2 of Supplementary Materials we include the comparison with the irradiated PMA samples that show no significant release performances.

We used the Weibull CDF, a distribution function of wide applicability $[45,59]$, for a statistical description of the entire release process, obtaining information on both simple and complex scenarios. Usually, simple scenarios correspond to release mechanisms based only on diffusion processes that can be described just by the Higuchi model or power law form [60]. As above mentioned, high exponents underlie the presence of complex release mechanisms such as polymer swelling plus erosion of matrix, and diffusion of drug taking place simultaneously $[58,61]$.

The Weibull non-normalized CDF can be written as:

$$
\mathrm{M}(t)=\mathrm{M}_{\infty}\left(1-e^{-\left(\frac{t}{\tau_{K}}\right)^{\beta}}\right)
$$

where $\mathrm{M}_{\infty}$ corresponds to the maximum released drug amount and $\tau_{K}$ and $\beta$ are constants related to the specific release mechanisms: their values have been correlated with the diffu- 
sion coefficient of matrices with high- and low-diffusivity areas [62]. The corresponding Weibull non-normalized PDF is then given by:

$$
f(t)=\frac{d \mathrm{M}(t)}{d t}=\mathrm{M}_{\infty} \frac{\beta}{\tau_{K}}\left(\frac{t}{\tau_{K}}\right)^{\beta-1} e^{-\left(\frac{t}{\tau_{K}}\right)^{\beta}}
$$

The Weibull function is one of the simplest distribution models, that can be used for multi-step chain processes such as survival in cancer. In such cases, $1 / \tau_{K}$ and $\beta$ represent a scale factor and a shape factor, respectively [56].

When the term $\left(\frac{t}{\tau_{K}}\right)^{\beta}$ is small, the Weibull function can be rewritten by taking a Taylor series expansion, so obtaining:

$$
\mathrm{M}(t)=\mathrm{M}_{\infty}\left(1-e^{-\left(\frac{t}{\tau_{K}}\right)^{\beta}}\right) \approx \mathrm{M}_{\infty}\left[1-\left(1-\left(\frac{t}{\tau_{K}}\right)^{\beta}\right)\right]=\mathrm{M}_{\infty}\left(\frac{t}{\tau_{K}}\right)^{\beta}
$$

that coincides with the power law form which, in turn, corresponds to the Higuchi law for $\beta=1 / 2$. Additionally, the cumulative Weibull distribution is the complementary function of the well-known stretched exponential form, widely used for the description of relaxation in disordered systems. It is called the Kohlrausch function, since it was launched by Rudolf Kohlrausch with the aim to explain the discharge of a capacitor [63], and can be generalized as:

$$
f(t)=e^{-\left(\frac{t}{\tau_{K}}\right)^{\beta}}
$$

The corresponding averaged relaxation time coincides with that of the Weibull function [49] being:

$$
\langle\tau\rangle=\int_{0}^{\infty} \mathrm{dt} \mathrm{e}^{-\left(\frac{t}{\tau_{K}}\right)^{\beta}}=\frac{\tau_{K}}{\beta} \Gamma\left(\frac{1}{\beta}\right)
$$

where $\Gamma$ is the Gamma function. The corresponding standard deviation (the square root of the variance) is given by:

$$
\sigma=\sqrt{\sigma^{2}}=\sqrt{\frac{\tau_{K}^{2}}{\beta}\left[2 \Gamma\left(\frac{2}{\beta}\right)-\frac{1}{\beta}\left(\Gamma\left(\frac{1}{\beta}\right)\right)^{2}\right]}
$$

\section{Discussion}

The drug release profiles for the irradiated and non-irradiated samples and their Weibull best-fit are reported in Figure 7a. The maximum saturation values were reached after $80 \mathrm{~h}$ and correspond to $0.012 \%$ for the non-irradiated system, and $15.1 \%$ and $27.8 \%$ for the nanocolloids and the electrospun nanofibers, respectively. In details, $5 \%$ of the drug was released within $20 \mathrm{~h}$ by the nanocolloids while in just $1 \mathrm{~h}$ by nanofibers. Additionally, the colloids reached the maximum amount of drug released just after $40 \mathrm{~h}$, whereas nanofibers continue releasing up to $\sim 70 \mathrm{~h}$. Further information was obtained from the Weibull fitting procedure setting $\mathrm{M}_{\infty}=0.012$ for the non-irradiated system: 15.1 and 27.8 for external stimulated colloids and nanofibers, respectively.

For the non-irradiated release, the shape parameter $\beta$, previously described and corresponding to a first-order release [58], and the characteristic time $\tau_{K}$ were estimated to be $1.01 \pm 0.07$ and $17.60 \pm 0.07 \mathrm{~h}$, respectively. For first order kinetics, the rate of release is governed by the concentration gradient in the dissolution medium [64] and, in such cases, the mean time $\langle\tau\rangle$ coincides with $\tau_{K}$. On the other side, analyzing the trend of the laser-induced drug release, we obtain:

- $\quad$ for the colloidal systems $\beta=(2.67 \pm 0.09), \tau_{K}=(27.90 \pm 0.04) h,\langle\tau\rangle=24.8 \mathrm{~h}$ and $\sigma=8.8 \mathrm{~h}$.

- $\quad$ for the scaffold systems $\beta=(0.71 \pm 0.02), \tau_{K}=(10.51 \pm 0.03) h,\langle\tau\rangle=13.1 \mathrm{~h}$, and $\sigma=23.6 \mathrm{~h}$. 

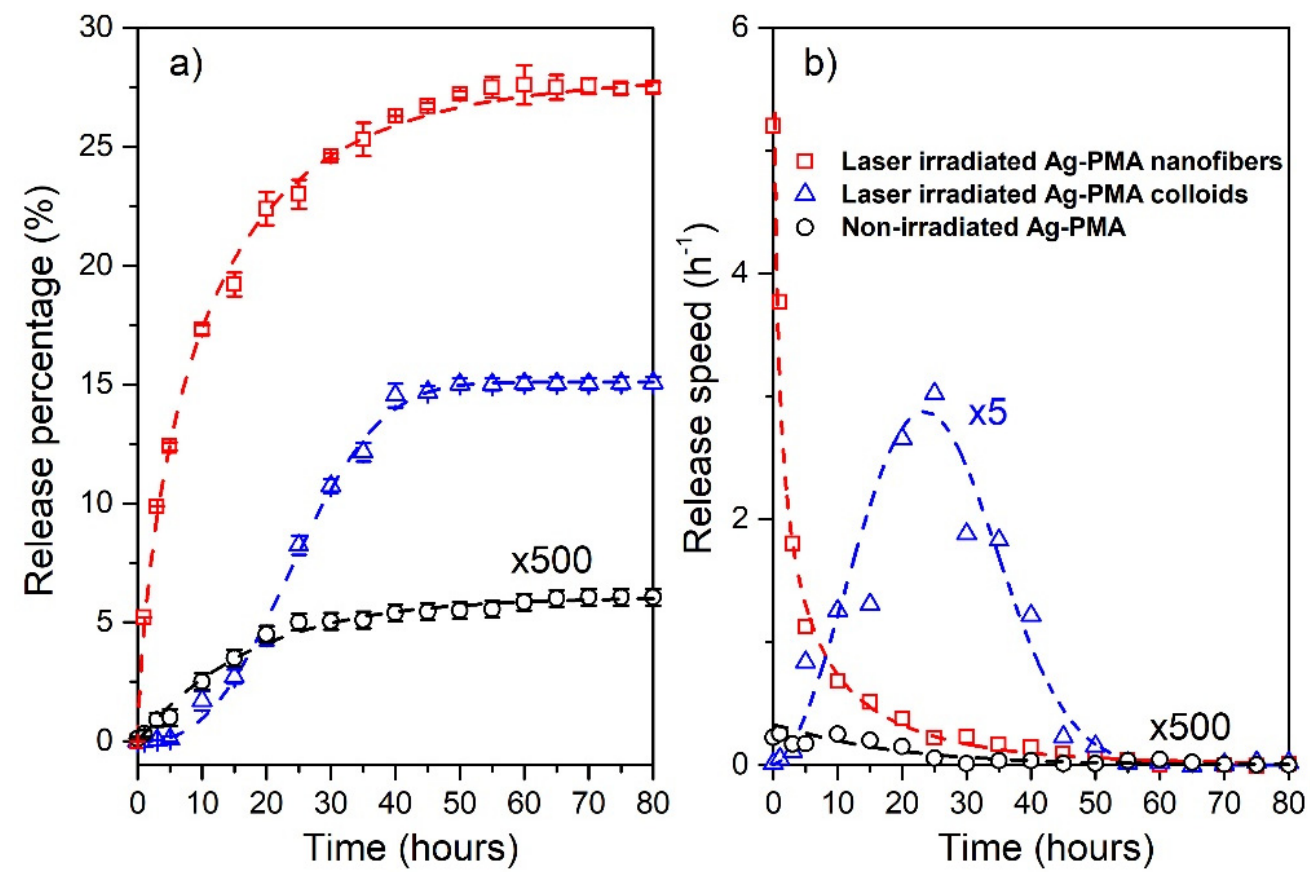

Figure 7. The release percentage vs. time and the corresponding best-fit performed with the use of the Weibull CDF (Equation (1)) (dashed lines) are reported in panel (a). The Weibull PDFs corresponding to the release data and fitted curves are reported in panel (b). Data for the non-irradiated system, referred to both colloids and nanofibers, are multiplied by a factor 500 . The release speed data for the irradiated colloids are multiplied by a factor 5. In Figure S3 of Supplementary Materials, we include the comparison with the irradiated PMA samples that show no significant release performances.

A value of $\beta \leq 0.75$ is associated with the Fick diffusion in either fractal or Euclidian spaces, while a combined mechanism (Fick diffusion and swelling controlled transport) is associated with $\beta$ values in the range $0.75<\beta<1$. For the shape factor $\beta>1$, the release mechanism is quite complex: the rate of release initially increases non-linearly up to the inflection point and thereafter decreases asymptotically $[58,65]$, as shown for the colloidal system (blue triangles and dashed line in Figure $7 \mathrm{~b}$ corresponding to the Weibull PDF for the experimental and modeled data, respectively). For what concerns the nanofiber system, a pronounced exponential character (for which the expected high standard deviation value) is observed by the release speed (Figure $7 \mathrm{~b}$ ), indicating a quicker and a more efficient release process whose character is mainly diffusive.

As mentioned in the Introduction section, the aim of this work is to study the influence of PMA properties, Ag NPs distribution and devices morphologies on the drug release efficiency. From a future perspective, the antioxidant and/or antimicrobial properties of these systems could be tested to reach responsive packaging systems. Weibull fitting represents a best practice to reproduce the whole life-time drug release process. Moreover, it is helpful in the comparison between the release profiles of matrix systems characterized by a different morphology (core/shell nanostructures, electrospun scaffolds, etc.). However, this model has no fundamental kinetic basis and cannot elucidate the release kinetic properties adequately since there is not a single parameter that is proportional to the intrinsic dissolution rate of the releasing drug. Despite that, a subsequent correlation between the profile-defining parameters and the samples' morphological properties (which, as is well-known, influence the dissolution time profile [66]) has been made, allowing determination of the dissolution efficiency of our nanosystems. The dissolution efficiency (DE) is defined by the Food and Drug Administration (FDA) and the European Medicines 
Agency (EMA) as the ratio between the area under the release profile up to a certain time $\left(t_{f}\right)$ and the area of the rectangle described by $100 \%$ release at the same $t_{f}$ [67]:

$$
\mathrm{DE}(\%)=\frac{\int_{0}^{t_{f}} \mathrm{M}(\mathrm{t}) \mathrm{dt}}{100 \times t_{f}} \times 100=\frac{\int_{0}^{t_{f}} \mathrm{M}_{\infty}\left(1-e^{-\left(\frac{t}{\tau_{K}}\right)^{\beta}}\right) \mathrm{dt}}{t_{f}}
$$

where $\mathrm{M}(\mathrm{t})$ is the Weibull non-normalized CDF reported in Equation (1). Herein, we have estimated DE values (see Table 1) both at fixed times $(40$ and $80 \mathrm{~h}$ ) and drug release percentages (5 and 10\%), to which different release mechanisms are associated. So, an attempt at prediction dissolution for a future optimized PMA based product has been proven trying to understand dissolution mechanism, particularly determining which individual rate processes (e.g., surface dissolution, diffusive mass transfer, scaffold disintegration) are rate-limiting for the overall dissolution for the two typologies of investigated samples (colloids and nanofibers scaffolds).

Table 1. DE values estimated both at fixed times ( 40 and $80 \mathrm{~h}$ ) and drug release percentages (5 and $10 \%)$, to which different release mechanisms are associated.

\begin{tabular}{cccc}
\hline & Time (hours) & Release (\%) & DE (\%) \\
\hline Nanofibers & 1 & 5 & 3 \\
& 3.5 & 10 & 6.3 \\
& 40 & 26 & 20.2 \\
& 80 & 28 & 23.6 \\
\hline Colloids & 20 & 5 & 1.5 \\
& 29 & 10 & 3.4 \\
& 40 & 14 & 5.9 \\
& 80 & 15 & 10.4 \\
\hline
\end{tabular}

As is well-known, the localized and intensive heating of Ag NPs, induced by the external laser light irradiation, results in the thermal expansion of the polymer, causing the drug diffusion [36]. This is the main mechanism reported to explain the drug release behavior in polymeric matrix decorated with metal NPs. In our case, the laser light is far from Ag SPR, and the drug release efficiency coming from the electrospun nanofibers is strongly increased with respect to the colloids and to the non-irradiated samples. The temperature increasing during the laser irradiation causes a rearrangement of non-covalent interactions in the PMA matrix leading to the hydrogen bonding dissociation of PMA complex units. In this transition phase, the hydrophilic and hydrophobic interactions within the polymer matrix, as well as between the polymer sidechains and the surrounding water molecules play a key role [68]. In fact, hydrophobic segments are surrounded by cagelike structures formed by water molecules bridged by hydrogen bonds. Upon increasing the temperature, thermal fluctuations destabilize the cage-like structures, inducing first the aggregation into hydrophobic clusters (known as volume phase transition) from which water molecules are expelled, and then the breakdown of hydrophobic segments for their direct contact with water molecules. All these processes are favored in the electrospun nanofibers where the increased surface area improved the sample wettability; in turn, the formation of hydrophobic barriers upon contact with water was avoided, leading to an enhancement of bioavailability of poor water-soluble drugs [18]. Hence, the porous nanofibers morphological reorganization (i.e., the increased surface/volume ratio) has resulted in significant changes of PMA surface properties, thus, creating a switchable polymeric system containing also an active element, responsive to the laser light external stimulus. From here, the release of SFT is faster in the electrospun sample than that of the colloid due to a higher diffusion rate.

In perspective, taking into account these preliminary results, a link between dissolution and clinical performance would ideally be established also providing a potential 
manufacturing tool for early-stage formulation development, a robust control strategy, real-time release testing, and flexibility toward post-approval changes. Furthermore, this work is interesting for researchers engaged in the fabrication of antimicrobial metallicpolymer-based nanocomposite system. The promising release data found about Ag-PMA systems led us to conduct antibacterial tests on Escherichia coli and Staphylococcus aureus to qualitatively evaluate their antibacterial activity. These preliminary results, shown in the Supplementary Materials (see Figure S1), are pivotal in view of the mentioned possible technological applications of these systems. In addition, despite the interesting antibacterial activity, tests on cytotoxicity, necrosis, and apoptosis using cell lines isolated from various human and animal tissues will be carried out.

\section{Conclusions}

Herein, Ag-PMA nanofiber scaffold was prepared by a safe and eco-friendly electrospinning procedure, starting from Ag-PMA colloidal solutions. Ag-PMA electrospun nanofibers were tested to be used as a carrier for a laser light-controlled drug release compared with the same colloidal system. The release profiles have been analyzed in terms of the Weibull statistical distribution function, which allows achievement of information about the processes that, damaging the stability of PMA compact system, govern the release mechanism. We believe that the reported results are interesting in perspective to establish a link between dissolution and clinical performance and are also considered important, from a manufacturing point of view, to fabricate controlled release packaging, i.e., a new generation of packaging materials that can release active compounds, such as antimicrobials and antioxidants, at desirable rates to extend the shelf life of a wide variety of foods. However, further studies closely combining the features of Ag-PMA found here with the potential applications related to technological/biomedical demands are still necessary and already scheduled.

Supplementary Materials: The following are available online at https://www.mdpi.com/article/ 10.3390/polym13172897/s1, Figure S1. Photos of bacterial culture plates of E. coli and S. aureus under PMA and Ag-PMA are shown in comparison with the control and Ag NPs; Figure S2. Log-log plot of the drug release percentage vs. time in hours for SFT embedded in PMA-Ag matrix at different conditions including irradiated PMA samples (a). Weibull plot of the same data (b). Data for the non-irradiated system refer to both colloids and nanofibers; Figure S3. The release percentage vs. time and the corresponding best-fit performed with the use of the Weibull CDF (Equation (1) of the paper) (dashed lines) are reported in panel a. The Weibull PDFs, describing the release speed profile corresponding to the release data and fitted curves, are reported in panel b. Data for the non-irradiated system, corresponding to both colloids and nanofibers, are multiplied by a factor 500 . Release data of PMA samples are multiplied by a factor 50 and the corresponding release speed by a factor 250. Finally, the release speed data for the irradiated colloids are multiplied by a factor 5 .

Author Contributions: All authors have contributed in an equal manner to the data interpretation and manuscript writing. Conceptualization, E.F.; data curation, G.N., C.C.; formal analysis, E.F., C.C.; investigation, A.M.M., G.N.; methodology, G.N., C.C., E.F.; writing-review and editing, G.N., C.C., A.M.M. and E.F. All authors have read and agreed to the published version of the manuscript.

Funding: This research received no external funding.

Institutional Review Board Statement: Not applicable.

Informed Consent Statement: Not applicable.

Data Availability Statement: The data presented in this study are available on request from the corresponding author.

Conflicts of Interest: The authors declare no conflict of interest. 


\section{References}

1. Santoro, A.; Holub, J.; Fik-Jaskółka, M.A.; Vantomme, G.; Lehn, J.-M. Dynamic Helicates Self-Assembly from Homo- and Heterotopic Dynamic Covalent Ligand Strands. Chem. A Eur. J. 2020, 26, 15664-15671. [CrossRef]

2. Puntoriero, F.; Arrigo, A.; Santoro, A.; Ganga, G.L.; Tuyèras, F.; Campagna, S.; Dupeyre, G.; Lainé, P.P. Photoinduced Intercomponent Processes in Selectively Addressable Bichromophoric Dyads Made of Linearly Arranged Ru(II) Terpyridine and Expanded Pyridinium Components. Inorg. Chem. 2019, 58, 5807-5817. [CrossRef] [PubMed]

3. Nastasi, F.; Santoro, A.; Serroni, S.; Campagna, S.; Kaveevivitchai, N.; Thummel, R.P. Early photophysical events of a ruthenium(ii) molecular dyad capable of performing photochemical water oxidation and of its model compounds. Photochem. Photobiol. Sci. 2019, 18, 2164-2173. [CrossRef] [PubMed]

4. Mancuso, A.; Barattucci, A.; Bonaccorsi, P.; Giannetto, A.; La Ganga, G.; Musarra-Pizzo, M.; Salerno, T.M.G.; Santoro, A.; Sciortino, M.T.; Puntoriero, F.; et al. Carbohydrates and Charges on Oligo (phenylenethynylenes): Towards the Design of Cancer Bullets. Chem. A Eur. J. 2018, 24, 16972-16976. [CrossRef] [PubMed]

5. Caccamo, D.; Currò, M.; Ientile, R.; Verderio, E.A.; Scala, A.; Mazzaglia, A.; Pennisi, R.; Musarra-Pizzo, M.; Zagami, R.; Neri, G.; et al. Intracellular Fate and Impact on Gene Expression of Doxorubicin/Cyclodextrin-Graphene Nanomaterials at Sub-Toxic Concentration. Int. J. Mol. Sci. 2020, 21, 4891. [CrossRef]

6. Cordaro, A.; Neri, G.; Sciortino, M.T.; Scala, A.; Piperno, A. Graphene-Based Strategies in Liquid Biopsy and in Viral Diseases Diagnosis. Nanomaterials 2020, 10, 1014. [CrossRef] [PubMed]

7. Celentano, W.; Neri, G.; Distante, F.; Li, M.; Messa, P.; Chirizzi, C.; Chaabane, L.; De Campo, F.; Metrangolo, P.; Baldelli Bombelli, F.; et al. Design of fluorinated hyperbranched polyether copolymers for 19F MRI nanotheranostics. Polym. Chem. 2020, 11, 3951-3963. [CrossRef]

8. Atta, O.M.; Manan, S.; Ahmed, A.A.Q.; Awad, M.F.; Ul-Islam, M.; Subhan, F.; Ullah, M.W.; Yang, G. Development and Characterization of Yeast-Incorporated Antimicrobial Cellulose Biofilms for Edible Food Packaging Application. Polymers 2021, 13, 2310. [CrossRef]

9. Khan, N.A.; Niazi, M.B.K.; Sher, F.; Jahan, Z.; Noor, T.; Azhar, O.; Rashid, T.; Iqbal, N. Metal Organic Frameworks Derived Sustainable Polyvinyl Alcohol/Starch Nanocomposite Films as Robust Materials for Packaging Applications. Polymers 2021, 13, 2307. [CrossRef]

10. Al-Tayyar, N.A.; Youssef, A.M.; Al-hindi, R. Antimicrobial food packaging based on sustainable Bio-based materials for reducing foodborne Pathogens: A review. Food Chem. 2020, 310, 125915. [CrossRef]

11. Zheng, L.; Sun, B.; Chen, Y.; Li, T.; Mao, S.; Zhu, S.; Wang, H.; Zhang, Y.; Lei, M.; Zhao, Y. The redox of hydroxyl-assisted metallic filament induced resistive switching memory based on a biomaterial-constructed sustainable and environment-friendly device. Mater. Today Chem. 2018, 10, 167-174. [CrossRef]

12. Zhang, A.; Jung, K.; Li, A.; Liu, J.; Boyer, C. Recent advances in stimuli-responsive polymer systems for remotely controlled drug release. Prog. Polym. Sci. 2019, 99, 101164. [CrossRef]

13. Raza, A.; Rasheed, T.; Nabeel, F.; Hayat, U.; Bilal, M.; Iqbal, H.M.N. Endogenous and Exogenous Stimuli-Responsive Drug Delivery Systems for Programmed Site-Specific Release. Molecules 2019, 24, 1117. [CrossRef] [PubMed]

14. He, Q.; Chen, J.; Yan, J.; Cai, S.; Xiong, H.; Liu, Y.; Peng, D.; Mo, M.; Liu, Z. Tumor microenvironment responsive drug delivery systems. Asian J. Pharm. Sci. 2020, 15, 416-448. [CrossRef]

15. Lionetto, F.; Esposito Corcione, C. Recent Applications of Biopolymers Derived from Fish Industry Waste in Food Packaging. Polymers 2021, 13, 2337. [CrossRef] [PubMed]

16. Abasian, P.; Ghanavati, S.; Rahebi, S.; Nouri Khorasani, S.; Khalili, S. Polymeric nanocarriers in targeted drug delivery systems: A review. Polym. Adv. Technol. 2020, 31, 2939-2954. [CrossRef]

17. Petlin, D.G.; Amarah, A.A.; Tverdokhlebov, S.I.; Anissimov, Y.G. A fiber distribution model for predicting drug release rates. J. Control. Release 2017, 258, 218-225. [CrossRef] [PubMed]

18. Sebe, I.; Szabó, P.; Kállai-Szabó, B.; Zelkó, R. Incorporating small molecules or biologics into nanofibers for optimized drug release: A review. Int. J. Pharm. 2015, 494, 516-530. [CrossRef]

19. Alkahtani, M.E.; Aodah, A.H.; Abu Asab, O.A.; Basit, A.W.; Orlu, M.; Tawfik, E.A. Fabrication and Characterization of FastDissolving Films Containing Escitalopram/Quetiapine for the Treatment of Major Depressive Disorder. Pharmaceutics 2021, 13, 891. [CrossRef]

20. Gorrasi, G.; Longo, R.; Viscusi, G. Fabrication and Characterization of Electrospun Membranes Based on "Poly ( $\varepsilon$-caprolactone)", "Poly(3-hydroxybutyrate)" and Their Blend for Tunable Drug Delivery of Curcumin. Polymers 2020, 12, 2239. [CrossRef]

21. Brockgreitens, J.; Abbas, A. Responsive Food Packaging: Recent Progress and Technological Prospects. Compr. Rev. Food Sci. Food Saf. 2016, 15, 3-15. [CrossRef]

22. Babikova, D.; Kalinova, R.; Momekova, D.; Ugrinova, I.; Momekov, G.; Dimitrov, I. Multifunctional Polymer Nanocarrier for Efficient Targeted Cellular and Subcellular Anticancer Drug Delivery. ACS Biomater. Sci. Eng. 2019, 5, $2271-2283$. [CrossRef] [PubMed]

23. Van Gheluwe, L.; Chourpa, I.; Gaigne, C.; Munnier, E. Polymer-Based Smart Drug Delivery Systems for Skin Application and Demonstration of Stimuli-Responsiveness. Polymers 2021, 13, 1285. [CrossRef] [PubMed] 
24. Krystyjan, M.; Khachatryan, G.; Grabacka, M.; Krzan, M.; Witczak, M.; Grzyb, J.; Woszczak, L. Physicochemical, Bacteriostatic, and Biological Properties of Starch/Chitosan Polymer Composites Modified by Graphene Oxide, Designed as New Bionanomaterials. Polymers 2021, 13, 2327. [CrossRef]

25. Gherasim, O.; Puiu, R.A.; Bîrcă, A.C.; Burdușel, A.-C.; Grumezescu, A.M. An Updated Review on Silver Nanoparticles in Biomedicine. Nanomaterials 2020, 10, 2318. [CrossRef] [PubMed]

26. Calabrese, G.; Petralia, S.; Franco, D.; Nocito, G.; Fabbi, C.; Forte, L.; Guglielmino, S.; Squarzoni, S.; Traina, F.; Conoci, S. A new Ag-nanostructured hydroxyapatite porous scaffold: Antibacterial effect and cytotoxicity study. Mater. Sci. Eng. C 2021, 118, 111394. [CrossRef]

27. Batista, R.A.; Espitia, P.J.P.; Quintans, J.d.S.S.; Freitas, M.M.; Cerqueira, M.Â.; Teixeira, J.A.; Cardoso, J.C. Hydrogel as an alternative structure for food packaging systems. Carbohydr. Polym. 2019, 205, 106-116. [CrossRef]

28. Mao, B.-H.; Chen, Z.-Y.; Wang, Y.-J.; Yan, S.-J. Silver nanoparticles have lethal and sublethal adverse effects on development and longevity by inducing ROS-mediated stress responses. Sci. Rep. 2018, 8, 2445. [CrossRef]

29. Domingo, G.; Bracale, M.; Vannini, C. Chapter 8-Phytotoxicity of Silver Nanoparticles to Aquatic Plants, Algae, and Microorganisms. In Nanomaterials in Plants, Algae and Microorganisms; Tripathi, D.K., Ahmad, P., Sharma, S., Chauhan, D.K., Dubey, N.K., Eds.; Academic Press: Cambridge, MA, USA, 2019; pp. 143-168. [CrossRef]

30. Bacchetta, C.; Ale, A.; Simoniello, M.F.; Gervasio, S.; Davico, C.; Rossi, A.S.; Desimone, M.F.; Poletta, G.; López, G.; Monserrat, J.M.; et al. Genotoxicity and oxidative stress in fish after a short-term exposure to silver nanoparticles. Ecol. Indic. 2017, 76, 230-239. [CrossRef]

31. Sulatha, M.S.; Natarajan, U. Molecular Dynamics Simulations of PAA-PMA Polyelectrolyte Copolymers in Dilute Aqueous Solution: Chain Conformations and Hydration Properties. Ind. Eng. Chem. Res. 2012, 51, 10833-10839. [CrossRef]

32. Yessine, M.-A.; Leroux, J.-C. Membrane-destabilizing polyanions: Interaction with lipid bilayers and endosomal escape of biomacromolecules. Adv. Drug Deliv. Rev. 2004, 56, 999-1021. [CrossRef] [PubMed]

33. Cárdenas, G.; Muñoz, C.; Carbacho, H. Thermal properties and TGA-FTIR studies of polyacrylic and polymethacrylic acid doped with metal clusters. Eur. Polym. J. 2000, 36, 1091-1099. [CrossRef]

34. Städler, B.; Price, A.D.; Zelikin, A.N. A Critical Look at Multilayered Polymer Capsules in Biomedicine: Drug Carriers, Artificial Organelles, and Cell Mimics. Adv. Funct. Mater. 2011, 21, 14-28. [CrossRef]

35. Neri, G.; Corsaro, C.; Fazio, E. Plasmon-Enhanced Controlled Drug Release from Ag-PMA Capsules. Molecules 2020, 25, 2267. [CrossRef]

36. Lumbreras-Aguayo, A.; Meléndez-Ortiz, H.I.; Puente-Urbina, B.; Alvarado-Canché, C.; Ledezma, A.; Romero-García, J.; Betancourt-Galindo, R. Poly (methacrylic acid)-modified medical cotton gauzes with antimicrobial and drug delivery properties for their use as wound dressings. Carbohydr. Polym. 2019, 205, 203-210. [CrossRef]

37. Lin, J.W.-P.; Dudek, L.P.; Majumdar, D. Wetting properties of homopolymers and copolymers of pentafluorostyrene and methylacrylate and homopolymer blends. J. Appl. Polym. Sci. 1987, 33, 657-667. [CrossRef]

38. Papra, A.; Gadegaard, N.; Larsen, N.B. Characterization of Ultrathin Poly (ethylene glycol) Monolayers on Silicon Substrates. Langmuir 2001, 17, 1457-1460. [CrossRef]

39. Ma, Y.; Cao, X.; Feng, X.; Ma, Y.; Zou, H. Fabrication of super-hydrophobic film from PMMA with intrinsic water contact angle below $90^{\circ}$. Polymer 2007, 48, 7455-7460. [CrossRef]

40. Spadaro, D.; Barletta, E.; Barreca, F.; Currò, G.; Neri, F. PMA capped silver nanoparticles produced by UV-enhanced chemical process. Appl. Surf. Sci. 2009, 255, 8403-8408. [CrossRef]

41. Spadaro, D.; Barletta, E.; Barreca, F.; Currò, G.; Neri, F. Synthesis of PMA stabilized silver nanoparticles by chemical reduction process under a two-step UV irradiation. Appl. Surf. Sci. 2010, 256, 3812-3816. [CrossRef]

42. Park, S.Y.; Kang, Z.; Thapa, P.; Jin, Y.S.; Park, J.W.; Lim, H.J.; Lee, J.Y.; Lee, S.-W.; Seo, M.-H.; Kim, M.-S.; et al. Development of sorafenib loaded nanoparticles to improve oral bioavailability using a quality by design approach. Int. J. Pharm. 2019, 566, 229-238. [CrossRef]

43. Weibull, W. A Statistical Distribution Function of Wide Applicability. J. Appl. Mech. 2021, 18, 293-297. [CrossRef]

44. Kolar-Anić, L.; Veljković, S.; Kapor, S.; Dubljević, B. Weibull distribution and kinetics of heterogeneous processes. J. Chem. Phys. 1975, 63, 663-668. [CrossRef]

45. Pourtalebi Jahromi, L.; Ghazali, M.; Ashrafi, H.; Azadi, A. A comparison of models for the analysis of the kinetics of drug release from PLGA-based nanoparticles. Heliyon 2020, 6, e03451. [CrossRef]

46. Koester, L.c.S.; Ortega, G.G.; Mayorga, P.; Bassani, V.L. Mathematical evaluation of in vitro release profiles of hydroxypropylmethylcellulose matrix tablets containing carbamazepine associated to $\beta$-cyclodextrin. Eur. J. Pharm. Biopharm. 2004, 58, 177-179. [CrossRef] [PubMed]

47. Ignacio, M.; Chubynsky, M.V.; Slater, G.W. Interpreting the Weibull fitting parameters for diffusion-controlled release data. Phys. A Stat. Mech. Appl. 2017, 486, 486-496. [CrossRef]

48. Paolino, D.; Tudose, A.; Celia, C.; Di Marzio, L.; Cilurzo, F.; Mircioiu, C. Mathematical Models as Tools to Predict the Release Kinetic of Fluorescein from Lyotropic Colloidal Liquid Crystals. Materials 2019, 12, 693. [CrossRef]

49. Mauro, J.C.; Smedskjaer, M.M. Unified physics of stretched exponential relaxation and Weibull fracture statistics. Phys. A Stat. Mech. Appl. 2012, 391, 6121-6127. [CrossRef] 
50. Neri, G.; Spadaro, S.; Barreca, F.; Santangelo, S.; Neri, F.; Fazio, E. Electrospun Ag/PMA Nanofibrous Scaffold as a Drug Delivery System. Curr. Nanomater. 2019, 4, 32-38. [CrossRef]

51. Neri, G.; Mion, G.; Pizzi, A.; Celentano, W.; Chaabane, L.; Chierotti, M.R.; Gobetto, R.; Li, M.; Messa, P.; De Campo, F.; et al. Fluorinated PLGA Nanoparticles for Enhanced Drug Encapsulation and 19F NMR Detection. Chem. A Eur. J. 2020, 26, 10057-10063. [CrossRef]

52. Fazio, E.; Scala, A.; Grimato, S.; Ridolfo, A.; Grassi, G.; Neri, F. Laser light triggered smart release of silibinin from a PEGylatedPLGA gold nanocomposite. J. Mater. Chem. B 2015, 3, 9023-9032. [CrossRef]

53. Spadaro, S.; Santoro, M.; Barreca, F.; Scala, A.; Grimato, S.; Neri, F.; Fazio, E. PEG-PLGA electrospun nanofibrous membranes loaded with $\mathrm{Au} @ \mathrm{Fe}_{2} \mathrm{O}_{3}$ nanoparticles for drug delivery applications. Front. Phys. 2017, 13, 136201. [CrossRef]

54. Zou, K.; Zhang, X.H.; Duan, X.F.; Meng, X.M.; Wu, S.K. Seed-mediated synthesis of silver nanostructures and polymer/silver nanocables by UV irradiation. J. Cryst. Growth 2004, 273, 285-291. [CrossRef]

55. Kora, A.J.; Rastogi, L. Enhancement of Antibacterial Activity of Capped Silver Nanoparticles in Combination with Antibiotics, on Model Gram-Negative and Gram-Positive Bacteria. Bioinorg. Chem. Appl. 2013, 2013, 871097. [CrossRef]

56. Mircioiu, C.; Voicu, V.; Anuta, V.; Tudose, A.; Celia, C.; Paolino, D.; Fresta, M.; Sandulovici, R.; Mircioiu, I. Mathematical Modeling of Release Kinetics from Supramolecular Drug Delivery Systems. Pharmaceutics 2019, 11, 140. [CrossRef] [PubMed]

57. Geraili, A.; Mequanint, K. Systematic Studies on Surface Erosion of Photocrosslinked Polyanhydride Tablets and Data Correlation with Release Kinetic Models. Polymers 2020, 12, 1105. [CrossRef]

58. Papadopoulou, V.; Kosmidis, K.; Vlachou, M.; Macheras, P. On the use of the Weibull function for the discernment of drug release mechanisms. Int. J. Pharm. 2006, 309, 44-50. [CrossRef] [PubMed]

59. Bruschi, M.L. Preface. In Strategies to Modify the Drug Release from Pharmaceutical Systems; Bruschi, M.L., Ed.; Woodhead Publishing: Cambridge, UK, 2015; pp. vii-viii. [CrossRef]

60. Higuchi, T. Rate of Release of Medicaments from Ointment Bases Containing Drugs in Suspension. J. Pharm. Sci. 1961, 50, 874-875. [CrossRef] [PubMed]

61. D'Souza, S.S.; Faraj, J.A.; DeLuca, P.P. A model-dependent approach to correlate accelerated with real-time release from biodegradable microspheres. AAPS Pharm. Sci. Tech. 2005, 6, E553-E564. [CrossRef]

62. Kosmidis, K.; Macheras, P. Monte Carlo simulations for the study of drug release from matrices with high and low diffusivity areas. Int. J. Pharm. 2007, 343, 166-172. [CrossRef]

63. Kohlrausch, R. Theorie des elektrischen Rückstandes in der Leidener Flasche. Ann. Phys. 1854, 167, 56-82. [CrossRef]

64. Rinaki, E.; Dokoumetzidis, A.; Macheras, P. The Mean Dissolution Time Depends on the Dose/Solubility Ratio. Pharm. Res. 2003, 20, 406-408. [CrossRef]

65. Kobryń, J.; Sowa, S.; Gasztych, M.; Dryś, A.; Musiał, W. Influence of Hydrophilic Polymers on the $\beta$ Factor in Weibull Equation Applied to the Release Kinetics of a Biologically Active Complex of Aesculus hippocastanum. Int. J. Polym. Sci. 2017, 2017, 3486384. [CrossRef]

66. Zaborenko, N.; Shi, Z.; Corredor, C.C.; Smith-Goettler, B.M.; Zhang, L.; Hermans, A.; Neu, C.M.; Alam, M.A.; Cohen, M.J.; Lu, X.; et al. First-Principles and Empirical Approaches to Predicting In Vitro Dissolution for Pharmaceutical Formulation and Process Development and for Product Release Testing. AAPS J. 2019, 21, 32. [CrossRef] [PubMed]

67. Cid, A.G.; Sonvico, F.; Bettini, R.; Colombo, P.; Gonzo, E.; Jimenez-Kairuz, A.F.; Bermúdez, J.M. Evaluation of the Drug Release Kinetics in Assembled Modular Systems Based on the Dome Matrix Technology. J. Pharm. Sci. 2020, 109, 2819-2826. [CrossRef]

68. Bagchi, B. Water in Biological and Chemical Processes: From Structure and Dynamics to Function; Cambridge University Press: Cambridge, UK, 2013. [CrossRef] 